\title{
The Impact of Momentary Pain and Fatigue on Physical Activity in Women With Osteoarthritis
}

\author{
SUSAN L. MURPHY, ${ }^{1}$ DYLAN M. SMITH, ${ }^{1}$ DANIEL J. CLAUW, ${ }^{2}$ AND NEIL B. ALEXANDER ${ }^{1}$
}

Objective. To examine the daily life patterns of both pain and fatigue symptoms and objective physical activity (using ambulatory monitoring) in women with symptomatic lower extremity osteoarthritis (OA), and to evaluate how momentary symptoms impact physical activity levels.

Methods. Sixty women age $\geq 55$ years ( 40 with knee or hip OA and 20 matched controls) participated in an observational study involving 2 laboratory visits and a 5-day home data collection period. During the home period physical activity levels were assessed continuously, and symptoms were inputted 6 times a day into an enhanced accelerometer at prespecified time points.

Results. In the OA group as compared with the control group over the 5-day period, average physical activity was significantly lower $(P=\mathbf{0 . 0 2})$ and peak physical activity tended to be lower $(P=0.06)$. Although pain and fatigue overall were of moderate severity in this cohort, fatigue escalated throughout each day. In a hierarchical linear model, fatigue was most strongly associated with physical activity $(\beta=-30.1, P<0.0001)$. Pain was more weakly associated with physical activity and in the direction opposite to what was hypothesized $(\beta=16.9, P=0.04)$.

Conclusion. Momentary reports of fatigue negatively predicted physical activity levels and were much more strongly related to physical activity than momentary pain. In order to help women with knee or hip OA manage symptoms and become more physically active, it may be important to emphasize fatigue management.

\section{INTRODUCTION}

Arthritis affects approximately 43 million adults in the US and is a leading cause of disability $(1,2)$. Arthritis treatment is associated with a large economic burden (estimated at $\$ 86$ billion in 1997) (3), which will likely become even greater with the projected increase of arthritis to $20 \%$ of the US population by 2030 (4).

In order to slow arthritis disease progression and dis-

Supported by the American College of Rheumatology Research and Education Foundation (Health Professional Investigator Award), the National Center for Research Resources (grant M01-RR-000042), the National Center for Medical Rehabilitation Research (grant K01-HD-045293), and the National Institute on Aging (grant K24-AG-109675).

${ }^{1}$ Susan L. Murphy, ScD, OTR, Dylan M. Smith, PhD, Neil B. Alexander, MD: University of Michigan and VA Ann Arbor Healthcare System, Ann Arbor, Michigan; ${ }^{2}$ Daniel J. Clauw, MD: University of Michigan, Ann Arbor.

Dr. Clauw has received consultant fees, speaking fees, and honoraria (less than $\$ 10,000$ each) from Wyeth and Forest and (more than \$10,000 each) from Lilly, Pfizer, and Cypress.

Address correspondence to Susan L. Murphy, ScD, OTR, 300 North Ingalls Street, Institute of Gerontology, 9th Floor, Ann Arbor, MI 48109-2007. E-mail: sumurphy@umich.edu.

Submitted for publication June 19, 2007; accepted in revised form January 3, 2008. ability, national efforts have focused on increasing physical activity (5). The health benefits of engaging in physical activity are well established and include maintenance of joint health and decreased severity of other common chronic health conditions (6-9). Among adults with arthritis, lack of regular physical activity is a risk factor for functional decline (10). Even participation in low-intensity activities has been found to be protective against the development of difficulty in activities of daily living such as stair climbing, walking, and bathing over a 2-year period (11).

Disease-associated symptoms pose obstacles to enhancing physical activity in arthritis. Osteoarthritis (OA), the most common form of arthritis, is often asymptomatic in individuals, but by far the most common symptom that leads an individual to seek a diagnosis and treatment is pain. People with knee or hip OA in particular may be limited by their joint pain in walking or mobility-related tasks. Pain is cited as a main cause of disability among older women with OA (12) and the link between pain and decreased physical functioning among those with OA is well established.

In contrast, although fatigue has not been nearly as well studied in OA (13), it is associated with decreased physical function and disability in mobility activities $(14,15)$. Whereas increased symptoms and decreased physical activity contribute to disability for people with OA, little is 
known about the interrelationships between them, particularly throughout the day.

Most previous studies of the relationship between symptoms and function in disease states have relied upon selfreport measures of symptoms and physical activity, and such measures are known to have inherent biases. Recall of symptom severity in particular likely leads to underreporting $(16,17)$, and retrospective symptom reports over a given time period (e.g., a week or a month) are influenced by peak or recent symptoms (17). In addition, self-report measures may be influenced by cognitive ability, fluctuations in mood, depression, anxiety, and changing health status (18). To deal with these biases, Ecological Momentary Assessment has been proposed, where participants enter their responses at several points throughout a day. Such assessments yield rich data about the symptom experience as it actually occurs within a person's daily routines.

Similarly, physical functioning is often measured using self-report measures. Although such measures are easy to administer, have excellent test-retest reliability, and are responsive to change, it is much less clear that they have face validity. In fact, several studies have suggested that self-report measures of physical function are poorly correlated with objective measures of physical activity such as accelerometry, both in patient groups and normal controls (19). Self-report measures of physical activity can also be influenced by recall bias and may underestimate physical activity in light- and moderate-intensity activities (20). These measures also provide little to no information about activity patterns throughout the day (21).

In this study, using Ecological Momentary Assessment, we examined the relationship between pain, fatigue, and physical activity over a 5-day period in women with symptomatic knee or hip OA. A wrist-worn accelerometer, the Actiwatch-S (Mini-Mitter, Bend, OR), was used to measure objective physical activity levels continuously over the 5-day period. The Actiwatch-S also prompted participants to input symptom severity reports in real time directly into the device at 6 points throughout the day. The purpose of this study was to examine the effect of momentary pain and fatigue symptoms on concurrent physical activity levels in daily life for women with symptomatic knee or hip OA. We hypothesized that increased pain and fatigue would be associated with decreased objective physical activity levels.

\section{PARTICIPANTS AND METHODS}

Sample. Forty women ages 55-80 years (mean \pm SD age $63.1 \pm 7.3$ years) with symptomatic knee or hip OA were recruited by posting fliers at clinics at the University of Michigan Medical Center, by contacting women who had joined a research participant registry maintained by the University of Michigan Claude D. Pepper Center, and through a University research participant Web site. Inclusion criteria consisted of 1) radiographic evidence of OA (Kellgren/Lawrence scale score $\geq 2$ ) in $\geq 1$ hip or knee, 2) reported pain in the joint with $\mathrm{OA}$ for $\geq 3$ months of at least mild severity ( $\geq 5$ on the Western Ontario and Mc-
Master Universities OA Index pain subscale) (22), 3) adequate cognition ( $\geq 24$ on the Mini Mental Status Exam), 4) ambulatory with or without an assistive device, and 5) the ability to see, hear, and operate the Actiwatch-S. Exclusion criteria consisted of 1) medical conditions that interfered with activity performance and caused pain and fatigue symptoms such as cardiopulmonary disorders, neurologic conditions, or autoimmune diseases, 2) current psychiatric disorders of schizophrenia or clinical depression, and 3) joint replacement or surgery within the previous 6 months.

Twenty healthy women control participants were age matched at a $2: 1$ ratio (mean \pm SD age $64.3 \pm 7.8$ years), in which each control participant was matched to 2 participants with OA. The largest age difference in matching was 5 years ( 1 match); however, $85 \%$ of matches were within 3 years of age difference. Controls were enrolled using the same inclusion and exclusion criteria as patients, except that controls neither had radiographic evidence of OA (i.e., Kellgren/Lawrence scale score $\leq 1$ ) nor reported joint pain. Eligible participants completed an informed consent form approved by the Institutional Review Board at the University of Michigan.

Procedure. Trained research personnel contacted interested women by phone to conduct an initial eligibility screening. If potential participants were eligible, radiographs were performed to determine presence (or absence) of hip and knee OA and its severity. All radiographs were interpreted by a blinded radiologist consultant. If eligible based on the radiograph findings, participants then completed a health interview, performance-based assessments, and questionnaires, and were instructed on the use of the Actiwatch-S and an accompanying log book (used for double-data entry and record of wake-up and bed times). Participants wore the Actiwatch-S on their nondominant wrist as instructed on a Sunday night and wore the device until the following Saturday morning, taking it off only to swim or shower/bathe. Participants recorded their symptom severity into the device 6 times daily, from Monday through Friday. Excluding the wake-up and bed time points, the Actiwatch-S emitted an audible prompt (previously programmed based on usual wake-up time) to alert participants to enter responses. The 6 time points were wake-up time, 2 hours after waking, 6 hours after waking, 10 hours after waking, 14 hours after waking, and 30 minutes before bed. Physical activity was collected continuously by the Actiwatch-S over the entire period. Participants then returned for a second laboratory visit to return the materials and complete the remaining assessments.

Measures. The main variables of interest, including physical activity, pain, and fatigue, were collected from the Actiwatch-S over a 5-day period, while women were engaged in their usual daily routines. Other variables collected during the laboratory visits ascertained demographics and potential covariates for use in the analyses.

Objective measures collected by the Actiwatch-S. Physical activity levels were measured using the Actiwatch-S, 
an omnidirectional actigraph accelerometer containing a piezo-electrode that records movements of $\geq 0.01 \mathrm{~g}$, a level of force that is sensitive enough to capture very minute movements. The actigraph samples acceleration changes 32 times per second, and the peak value is added to an accumulated value over a 15-second epoch, which is recorded as an activity count. Actiwatch accelerometers have been used in previous studies to measure physical activity in adults who have chronic pain $(19,23,24)$. The wrist-worn Actiwatch-S was found to discriminate between peak and high-level activity among patients with fibromyalgia and controls (19). It has also demonstrated excellent interdevice reliability mounted at the wrist $(\mathrm{r}=0.98)$ and has established preliminary criterion validity among a sample of patients with mild chronic pain (25). No studies could be found among older adults with or without chronic pain that had established activity count cut points for low-, moderate-, and high-intensity physical activities. However, for accelerometers in general, higher activity counts reflect participation in higher intensity activities (26).

Prior to analysis, data from the Actiwatch-S were downloaded into the computer. The actograms were first scanned visually for signs of device malfunction (such as a consistent pattern of unusually low readings) and then verified against the participant's daily logs for completeness. Four days of complete activity data were considered necessary to be included in the analysis. Because participants were asked to wear the device continuously for 5 days, it was necessary to establish their wake-up and bed times. A previously established algorithm was used for this purpose $(19,27)$. In addition, periods where participants indicated taking off the watch on the daily logs were excluded, as well as any period of a 10-minute run of zero activity counts. Activity levels were measured at intervals that were set corresponding to the symptom reports within each day (i.e., morning, mid-morning, afternoon, evening, before bed) and were assessed in 2 ways. The average activity count per minute (average physical activity) was an aggregate of all activity counts recorded per minute over an interval, and the peak activity count (peak physical activity) was the highest activity count that occurred during an interval. Average and peak physical activity were also examined as a total score, that is, by averaging all within-day values over the 5-day period, excluding missing data that occurred from temporary removal of the Actiwatch-S (19,27).

Subjective measures collected by the Actiwatch-S. Pain and fatigue, which was defined as tiredness or weariness (13), were measured by ratings on visual analog scales for severity (where $0=$ none and $4=$ extremely severe). These ratings were inputted into the device as well as recorded in a daily log in order to cross-validate the items. The log was used as a backup if there were missing data or if participants accidentally recorded an extra response into the device. Participants also used the log to record daily medication use of the medications taken for pain, to track their daily activities, and to record their wake-up and bed times. The wake-up and bed times were recorded in order to best interpret the physical activity levels assessed by the Actiwatch-S.

Other self-report measures. Demographic characteristics included age, education, marital status, race/ethnicity, and employment. Depressive symptoms were measured by the Geriatric Depression Scale (28). Self-reported physical disability was assessed by the Established Population for Epidemiologic Studies in the Elderly Battery (29), in which people report difficulty or inability in performing 15 tasks, including activities of daily living and mobility (such as stair climbing or pushing or pulling large objects). To examine the extent of overall joint pain, all participants were asked which joints were painful or stiff (including shoulders, fingers/wrists, elbows, spine, hip, knees, or other joints). The number of painful joints was tallied and a total summary score was created. Participants also provided names of all prescription medications taken within the previous 2 weeks. Prescription medications were then tallied.

Other objective measures. The Timed Up and Go Test (time taken to rise from a chair, walk 3 meters, and return to the chair) (30) was used as a measure of physical function; in this case, functional mobility. Participants performed 3 trials and the averaged value was used in the analysis. Isometric extension torque of the right knee was assessed using an isokinetic dynamometer (Biodex Multisystem 2AP; Biodex Medical, Shirley, NJ), using standard positioning and testing procedures.

Statistical analysis. Demographic, health status, and physical performance characteristics of women with OA and controls were compared using $t$-tests or chi-square tests. Pain, fatigue, average physical activity, and peak physical activity were averaged across each time point for each group and were also averaged over the 5-day period for total aggregate scores. For women with OA, the relationship between pain, fatigue, and physical activity over the 5-day period was examined using a 2-level hierarchical linear regression model. This method is commonly used with repeated measures data and takes into account different levels of variation that occur both within and between participants (31). In the final model, the dependent variable was average physical activity and the independent variables were individual observations of pain and fatigue. Because the model comprised only the women with OA, it did not control for all variables in which significant group differences were found. Instead, covariates were chosen given their relationship to physical activity. Given the association between participation in physical activity and age $(32,33)$, body mass index (BMI) (32-34), depressive symptoms (34), and physical function $(10,11,35)$, these variables were also included as covariates in the analysis, along with daily pain medication use. Although race $(32,33)$ and education status $(32,34)$ were also associated with participation in physical activity, these were not included in the analysis as covariates, given the low variability among our sample of participants with OA. Lastly, between-subjects factors of pain and fatigue were also 


\begin{tabular}{|c|c|c|c|}
\hline & $\begin{array}{l}\text { With OA } \\
(n=40)\end{array}$ & $\begin{array}{l}\text { Without OA } \\
(n=20)\end{array}$ & $\boldsymbol{P}$ \\
\hline Age, years & $63.1 \pm 7.3$ & $64.3 \pm 7.8$ & 0.57 \\
\hline Bachelors or advanced degree, no. (\%) & $25(63)$ & $12(60)$ & 0.85 \\
\hline Married, no. (\%) & $21(53)$ & $12(60)$ & 0.58 \\
\hline White, no. (\%) & $35(88)$ & $19(95)$ & $0.65+$ \\
\hline Works $\geq 20$ hours/week, no. (\%) & $18(45)$ & $7(35)$ & 0.46 \\
\hline Body mass index, $\mathrm{kg} / \mathrm{m}^{2}$ & $31.0 \pm 5.6$ & $24.7 \pm 3.8$ & 0.0001 \\
\hline Geriatric Depression Scale score & $2.1 \pm 2.5$ & $0.5 \pm 0.7$ & 0.001 \\
\hline Number of prescription medications at baseline & $2.8 \pm 2.4$ & $1.6 \pm 1.6$ & 0.04 \\
\hline Daily pain medication use, no. (\%)‡ & $23(58)$ & $1(5)$ & 0.0001 \\
\hline Number of painful or stiff joints & $3.9 \pm 1.7$ & $1.7 \pm 1.7$ & 0.0001 \\
\hline Self-reported disability, EPESE score & $3.2 \pm 1.4$ & $1.0 \pm 1.2$ & 0.0001 \\
\hline Timed Up and Go Test, seconds & $9.8 \pm 2.3$ & $8.0 \pm 1.2$ & 0.0004 \\
\hline Right knee extension torque, Nm & $91.1 \pm 36.8$ & $95.8 \pm 30.5$ & 0.68 \\
\hline \multicolumn{4}{|c|}{$\begin{array}{l}\text { *Values are the mean } \pm \text { SD unless otherwise indicated. OA = osteoarthritis; EPESE = Established Population for Epidemiologic } \\
\text { Studies in the Elderly Battery; Nm = Newton meters. } \\
\text { † By Fisher’s exact test due to low cell counts. } \\
\text { キ Number of people who used pain medication on any day over the 5-day home data collection period. }\end{array}$} \\
\hline
\end{tabular}

included in the model to examine if the relationship between momentary symptoms and physical activity varied by participant.

\section{RESULTS}

A total of 142 women were screened for potential inclusion in the study. Of these, $22(16 \%)$ were screened out by the phone screening (either due to not having enough baseline pain per the criteria for potential participants with OA or having other conditions that interfered with activity performance) (22); 43 (30\%) were ineligible based on radiographic findings; and $17(12 \%)$ refused to participate before or after the radiograph appointment. The remaining sample included 60 participants (mean \pm SD age $64.0 \pm 7.5$ years), including 40 with symptomatic knee or hip OA (37 with knee OA and 3 with hip OA) and 20 age-matched controls.

When compared with controls, women with symptomatic knee or hip OA had a significantly higher mean BMI, more depressive symptoms, a higher number of prescription medications taken, a higher number of painful or stiff joints, more self-reported disability, and slower functional mobility (as measured by the Timed Up and Go Test). Over the 5-day home data collection period, 58\% of women with OA took pain medication at least once compared with $5 \%$ of controls. The groups did not significantly differ in years of education received, marital status, race, or in physical characteristics of gait or knee extension torque (Table 1).

Women with symptomatic knee or hip OA had significantly more total pain and fatigue than controls over the 5-day period; however, these aggregated symptom scores reflected modest severity overall (mean score 1, range 0-4) (Table 2). In the OA group compared with controls over the 5-day period, average physical activity was significantly lower $(P=0.02)$, and peak physical activity tended to be lower $(P=0.06)$. Upon examination of symptom and activity patterns over the 5-day period, group tendencies were found. Almost no pain was experienced in the control group over the 5-day period, whereas the OA group overall experienced moderate pain with little variation in severity within each day (Figure 1). For both groups, fatigue escalated throughout each day; however, this escalation was steeper and of higher severity in the OA group when compared with the control group (Figure 2). Women with OA had lower average and peak physical activity patterns over the 5-day period compared with controls (Figure 3).

The relationship between momentary symptoms of pain and fatigue and physical activity was examined using hierarchical linear modeling. Table 3 shows the final model, controlling for potential confounding factors of age, BMI, depressive symptoms, daily pain medication use, and

Table 2. Pain, fatigue, and physical activity levels averaged over all time points for older women with and without symptomatic knee or hip osteoarthritis $(\mathrm{OA})^{*}$

\begin{tabular}{|lccc|}
\hline & $\begin{array}{c}\text { With OA } \\
(\mathbf{n}=\mathbf{4 0})\end{array}$ & $\begin{array}{c}\text { Without OA } \\
\text { (n= 20) }\end{array}$ & $\boldsymbol{P}$ \\
\hline Pain & $1.1 \pm 0.7$ & $0.04 \pm 0.1$ & 0.0001 \\
Fatigue & $1.1 \pm 0.7$ & $0.3 \pm 0.5$ & 0.0001 \\
Average physical activity, activity count/minute & $317.8 \pm 89.5$ & $380.0 \pm 106.1$ & 0.02 \\
Peak physical activity, activity count & $595.1 \pm 137.2$ & $669.3 \pm 144.3$ & 0.06 \\
\hline * Values are the mean \pm SD. & & & \\
\hline
\end{tabular}




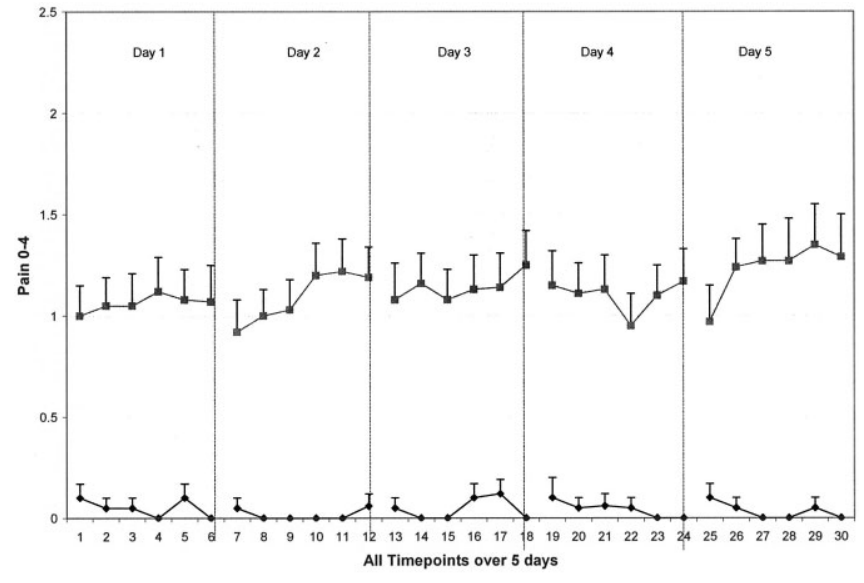

Figure 1. Pain of 40 women with symptomatic osteoarthritis (solid squares) and 20 controls (solid diamonds). Means and SEs are shown.

functional mobility, as well as subject-level variables of fatigue and pain. The subject-level variables included average pain and fatigue across participants to account for any between-subject effects. In this model, momentary fatigue was significantly negatively associated with physical activity as hypothesized. The model shows that as fatigue increased by 1 unit, activity counts per minute decreased by 30.1. Momentary pain was more weakly associated with physical activity, and in the opposite direction from what was expected: as pain increased, activity counts per minute also increased by 16.9. Functional mobility was significantly negatively associated with physical activity; that is, participants with lower functional mobility engaged in less physical activity. Because pain and fatigue were moderately correlated $(\mathrm{r}=0.51)$, we also ran the models above separately for pain and fatigue. In these models, momentary fatigue was significantly negatively associated with physical activity when momentary pain was absent from the model $(\beta=-23.7, P<0.0001)$, and momentary pain was not significantly associated with physical activity when momentary fatigue was absent from the model $(\beta=6.6, P=0.43)$.

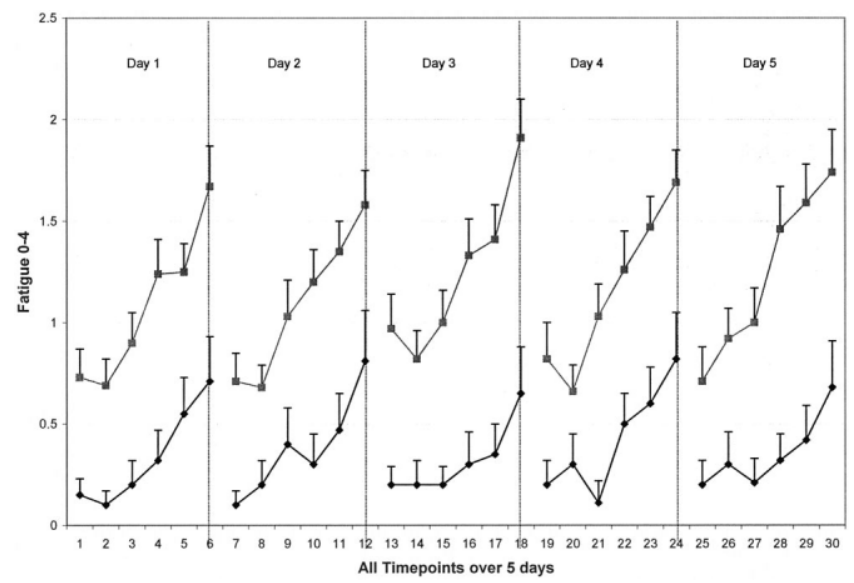

Figure 2. Fatigue of 40 women with symptomatic osteoarthritis (solid squares) and 20 controls (solid diamonds). Means and SEs are shown.

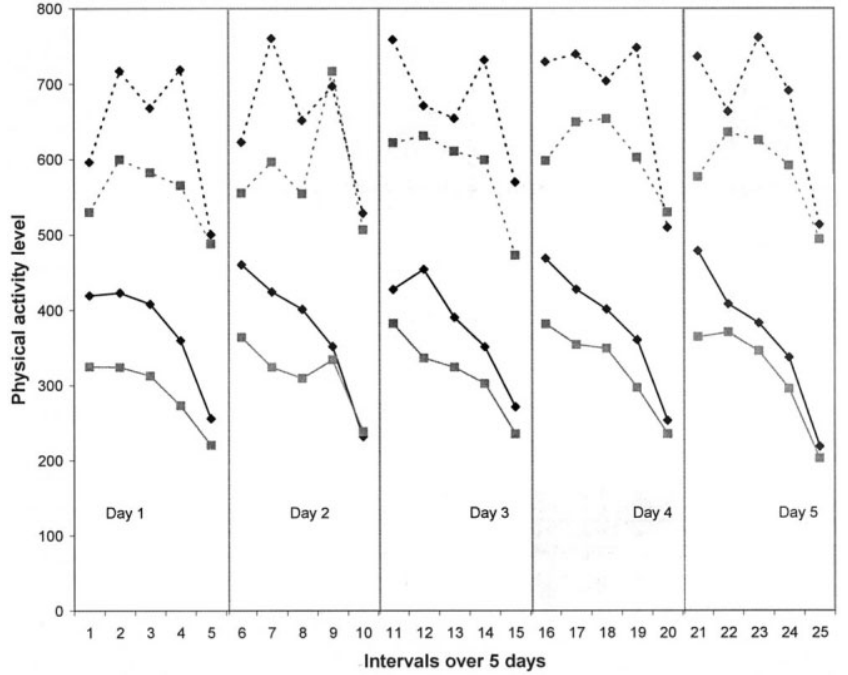

Figure 3. Peak physical activity (broken lines) and average physical activity (solid lines) for 40 women with symptomatic osteoarthritis (solid squares) and 20 controls (solid diamonds).

\section{DISCUSSION}

To our knowledge, this is the first study that examines both objective physical activity levels and within-day symptoms in a sample of women with symptomatic knee or hip OA. In the OA group as compared with the control group over the 5-day period, average physical activity was significantly lower $(P=0.02)$ and peak physical activity tended to be lower $(P=0.06)$. Physical activity patterns tended to be lower at almost every time point within each day during the 5-day period.

The objective measurement of all physical activity that occurs in daily life over a specified time period as done in this study may be a particularly important measurement method for future physical activity studies. For example, using this method may lead to a better delineation of the health benefits of engaging in physical activity for people with OA. The large body of evidence supporting positive

\begin{tabular}{|c|c|c|c|}
\hline \multicolumn{4}{|c|}{$\begin{array}{l}\text { Table 3. The relationship between physical activity and } \\
\text { symptoms of fatigue and pain, controlling for other } \\
\text { factors in older women with osteoarthritis }(n=40)^{*}\end{array}$} \\
\hline & $\beta$ estimate & SE & $\boldsymbol{P}$ \\
\hline Fatigue & -30.08 & 6.21 & $<0.0001$ \\
\hline Pain & 16.86 & 8.36 & 0.04 \\
\hline Age, years & -2.43 & 1.79 & 0.18 \\
\hline Body mass index, $\mathrm{kg} / \mathrm{m}^{2}$ & -4.31 & 2.58 & 0.11 \\
\hline $\begin{array}{l}\text { Geriatric Depression Scale } \\
\text { score }\end{array}$ & -7.52 & 5.40 & 0.17 \\
\hline Daily pain medication use & -2.07 & 14.50 & 0.89 \\
\hline $\begin{array}{l}\text { Timed Up and Go Test, } \\
\text { seconds }\end{array}$ & -14.30 & 6.00 & 0.02 \\
\hline Average fatigue & -24.55 & 24.68 & 0.33 \\
\hline Average pain & 34.29 & 23.85 & 0.16 \\
\hline \multicolumn{4}{|c|}{$\begin{array}{l}\text { * The model was adjusted for daily pain medication use over the } \\
\text { 5-day period and the following subject level variables to control for } \\
\text { between-subject variation: age (years), body mass index, depressive } \\
\text { symptoms (Geriatric Depression Scale), and average levels of fatigue } \\
\text { and pain across subjects. }\end{array}$} \\
\hline
\end{tabular}


health effects of physical activity is primarily derived from studies that examined participation in structured exercise programs. There is less evidence about health effects of participating in other forms of physical activity such as leisure time activity or lifestyle physical activity. It was recently demonstrated that participation in lifestyle physical activity (such as housework and climbing stairs) improves mortality risk (36). Other interventions that are designed to integrate physical activity (such as walking and stair climbing) into daily routines have shown effects of improved physical fitness in obese women (37) and improved physical function and pain in recent breast cancer survivors (38).

Pain and fatigue symptoms contribute to disability among people with OA (12-15) and may be a barrier to engaging in physical activity. Therefore, we hypothesized that increased momentary pain and fatigue severity would be associated with decreased physical activity. This hypothesis was only partially supported. Interestingly, only fatigue was negatively associated with physical activity after controlling for other factors. The results also show that more functional mobility impairment is related to decreased physical activity, which is similar to findings in a previous study (11).

In this study, we observed a significant positive relationship between pain and physical activity, but only when fatigue was also included in the model, demonstrating a suppressor effect (39). Because of the collinearity between pain and fatigue, along with the negative association between fatigue and physical activity, the positive relationship between pain and physical activity is suppressed when fatigue is absent from the model. In addition, the relationship of pain and physical activity is in the opposite direction from what was expected. The results show that increased momentary pain was associated with increased physical activity. In qualitative studies, pain has been cited as a barrier to participating in physical activity among people with arthritis $(40,41)$. However, regular exercisers reported participating in exercise despite their pain levels in order to maintain their level of fitness, and noted reductions in symptoms because of exercising (40). Therefore, it is possible that participants with OA may be engaging in physical activity to help manage their pain. Another possible explanation may be that the sample experienced only moderate pain severity overall. However, the average pain level of just over 1 on a $0-4$ scale likely represents a corresponding value of $\geq 3$ on a typical $0-10$ visual analog scale, because it is known that patients tend to rate their pain higher on paper-and-pencil measures taken in the clinic than on corresponding momentary assessments $(42,43)$. Nonetheless, it is possible that examination of momentary symptoms and physical activity in a more symptomatic cohort may yield different results.

Despite the moderate pain severity experienced by the sample of women with OA in this study, the finding that fatigue significantly impacted physical activity has potentially important implications for OA management and future research. Treatment for arthritis (whether surgical, pharmacologic, or nonpharmacologic) mainly targets OA pain. This study provides support to broaden the focus on pain management to also include fatigue. Although pain was associated with fatigue in this study and in other studies of OA patients $(13,44)$, the mechanisms of fatigue in people with OA remain unclear. A better understanding of fatigue in OA should lead to more focused interventions to enhance physical activity. In knee OA, it is hypothesized that quadriceps fatigue during prolonged walking in older, obese people may contribute to OA development and progression (45). The experience of fatigue is likely to be multifaceted. In a recent study, higher daily fatigue in women with OA was associated with lower positive affect (44). The relationship between fatigue and depressive symptoms also appears to be an important area of future inquiry, given the increased prevalence in depression among people with $\mathrm{OA}$ and the association between depression, chronic pain, and physical inactivity (46).

Possible limitations include the sample of women who were highly educated, predominantly white, and had moderate pain, thereby influencing generalizability to more diverse and painful samples. A 0-4 rating scale of pain and fatigue was used in this study as opposed to the more common 0-10 scale of symptom severity. A smaller scale was chosen to reduce respondent burden into the Actiwatch-S, but may limit comparability with other studies. In addition, participant use of arthritis pain medication (whether over-the-counter or prescription) was not an exclusion criterion in this study. Despite the use of medications, participants still reported pain at mild or higher levels at baseline, which was appropriate for this study. Exclusion of participants taking only prescription medications may have yielded a more painful sample but would have limited generalizability. Lastly, a recent study of validity of the Actiwatch-S found that measurement of specific daily activities is affected by placement of the device (25). However, wearing the Actiwatch-S on the wrist was the optimal method to examine daily routine patterns, including sleep and wake-up periods, and was necessary in order to enter responses into the Actiwatch-S several times a day.

In summary, we found that women with OA had increased pain and fatigue symptoms and decreased physical activity when compared with age-matched controls. Fatigue had a strong negative relationship to physical activity and appears to be an important symptom to examine in future studies of OA. Although symptom management interventions largely focus on pain, it may be important to have a better emphasis on fatigue management.

\section{AUTHOR CONTRIBUTIONS}

Dr. Murphy had full access to all of the data in the study and takes responsibility for the integrity of the data and the accuracy of the data analysis.

Study design. Murphy, Clauw, Alexander.

Acquisition of data. Murphy.

Analysis and interpretation of data. Murphy, Smith, Alexander. Manuscript preparation. Murphy, Smith, Clauw, Alexander. Statistical analysis. Murphy, Smith.

\section{REFERENCES}

1. Centers for Disease Control and Prevention (CDC). Prevalence of disabilities and associated health conditions among adults: 
United States, 1999 [published erratum appears in MMWR Morb Mortal Wkly Rep 2001;50:149]. MMWR Morb Mortal Wkly Rep 2001;50:120-5.

2. Hootman JM, Langmaid G, Helmick CG, Bolen J, Kim I, Shih $\mathrm{M}$, et al. Monitoring progress in arthritis management: United States and 25 states, 2003. MMWR Morb Mortal Wkly Rep $2005 ; 54: 484-8$.

3. Murphy L, Cisternas M, Yelin E, Trupin L, Helmick CG. Update: direct and indirect costs of arthritis and other rheumatic conditions. United States, 1997. MMWR Morb Mortal Wkly Rep 2004;53:388-9.

4. Centers for Disease Control and Prevention (CDC). Public health and aging: projected prevalence of self-reported arthritis or chronic joint symptoms among persons aged $\geq 65$ years. United States, 2005-2030. MMWR Morb Mortal Wkly Rep 2003;52:489-91.

5. Meenan RF, Callahan LF, Helmick CG. The National Arthritis Action Plan: a public health strategy for a looming epidemic [editorial]. Arthritis Care Res 1999;12:79-81.

6. Pate RR, Pratt M, Blair SN, Haskell WL, Macera CA, Bouchard $\mathrm{C}$, et al. Physical activity and public health: a recommendation from the Centers for Disease Control and Prevention and the American College of Sports Medicine. JAMA 1995;273: $402-7$.

7. Taylor AH, Cable NT, Faulkner G, Hillsdon M, Narici M, Van Der Bij AK. Physical activity and older adults: a review of health benefits and effectiveness of interventions. J Sports Sci 2004;22:703-25.

8. Kahn EB, Ramsey LT, Brownson RC, Heath GW, Howze EH, Powell KE, et al. The effectiveness of interventions to increase physical activity: a systematic review. Am J Prev Med 2002; 22(4 Suppl):73-107.

9. Karmisholt K, Gyntelberg F, Gotzche PC. Physical activity for primary prevention of disease: systematic reviews of randomized clinical trials. Dan Med Bull 2005;52:86-9.

10. Dunlop DD, Semanik P, Song J, Manheim LM, Shih V, Chang RW. Risk factors for functional decline in older adults with arthritis. Arthritis Rheum 2005;52:1274-82.

11. Feinglass J, Thompson JA, He XZ, Witt W, Chang RW, Baker DW. Effect of physical activity on functional status among older middle-age adults with arthritis. Arthritis Rheum 2005; 53:879-85.

12. Leveille SG, Fried L, Guralnik JM. Disabling symptoms: what do older women report? J Gen Intern Med 2002;17:766-73.

13. Wolfe F, Hawley DJ, Wilson K. The prevalence and meaning of fatigue in rheumatic disease. J Rheumatol 1996;23:140717.

14. Avlund K, Vass M, Hendriksen C. Onset of mobility difficulty among community-dwelling old men and women: the role of tiredness in activities. Age Ageing 2003;32:579-84.

15. Wolfe F. Determinants of WOMAC function, pain, and stiffness scores: evidence for the role of back pain, symptom counts, fatigue and depression in osteoarthritis, rheumatoid arthritis, and fibromyalgia. Rheumatology (Oxford) 1999;38: 355-61.

16. Gignac MA, Cott C, Badley EM. Adaptation to chronic illness and disability and its relationship to perceptions of independence and dependence. J Gerontol B Psychol Sci Soc Sci 2000;55:P362-72.

17. Stone AA, Turkkan JS, Bachrach CA, Jobe JB, Kurtzman HS, Cain VS, editors. The science of self-report: implications for research and practice. Mahwah (NY): Lawrence Erlbaum; 1999.

18. Rikli RE. Reliability, validity, and methodological issues in assessing physical activity in older adults. Res Q Exerc Sport 2000;71(2 Suppl):S89-96.

19. Kop WJ, Lyden A, Berlin AA, Ambrose K, Olsen C, Gracely $\mathrm{RH}$, et al. Ambulatory monitoring of physical activity and symptoms in fibromyalgia and chronic fatigue syndrome. Arthritis Rheum 2005;52:296-303.

20. Washburn RA. Assessment of physical activity in older adults. Res Q Exerc Sport 2000;71(2 Suppl):S79-88.
21. Davis MG, Fox KR. Physical activity patterns assessed by accelerometry in older people. Eur J Appl Physiol 2007;100: 581-9.

22. Topp R, Woolley S, Hornyak J 3rd, Khuder S, Kahaleh B. The effect of dynamic versus isometric resistance training on pain and functioning among adults with osteoarthritis of the knee. Arch Phys Med Rehabil 2002;83:1187-95.

23. Liszka-Hackzell JJ, Martin DP. An analysis of the relationship between activity and pain in chronic and acute low back pain. Anesth Analg 2004;99:477-81.

24. Liszka-Hackzell JJ, Martin DP. Analysis of nighttime activity and daytime pain in patients with chronic back pain using a self-organizing map neural network. J Clin Monit Comput 2005;19:411-4.

25. Gironda RJ, Lloyd J, Clark ME, Walker RL. Preliminary evaluation of reliability and criterion validity of Actiwatch-Score. J Rehabil Res Dev 2007;44:223-30.

26. Swartz AM, Strath SJ, Bassett DR Jr, O’Brien WL, King GA, Ainsworth BE. Estimation of energy expenditure using CSA accelerometers at hip and wrist sites. Med Sci Sports Med 2000;32(9 Suppl):S450-6.

27. Murphy SM, Smith DM, Alexander NB. Measuring activity pacing in women with osteoarthritis: a pilot study. Am J Occup Ther. In press.

28. Yesavage JA, Brink TL, Rose TL, Lum O, Huang V, Adey M, et al. Development and validation of a Geriatric Depression Rating Scale: a preliminary report. J Psychiatr Res 1983;17:3749.

29. Smith LA, Branch LG, Scherr PA, Wetle T, Evans DA, Hebert L, et al. Short-term variability of measures of physical function in older people. J Am Geriatr Soc 1990;38:993-8.

30. Podsiadlo D, Richardson S. The timed "Up \& Go": a test of basic functional mobility for frail elderly persons. J Am Geriatr Soc 1991;39:142-8.

31. Singer JD. Using SAS PROC MIXED to fit multi-level models, hierarchical models, and individual growth models. J Educ Behav Stat 1998;23:323-55.

32. Hootman JM, Macera CA, Ham SA, Helmick CG, Sniezek JE. Physical activity levels among the general US population and in adults with and without arthritis. Arthritis Rheum 2003; 49:129-35.

33. Fontaine KR, Haaz S. Risk factors for lack of recent exercise in adults with self-reported, professionally diagnosed arthritis. J Clin Rheumatol 2006;12:66-9.

34. Walsh JM, Pressman AR, Cauley JA, Browner WS. Predictors of physical activity in community-dwelling elderly white women. J Gen Intern Med 2001;16:721-7.

35. Brach JS, FitzGerald S, Newman AB, Kelsey S, Kuller L, VanSwearingen JM, et al. Physical activity and functional status in community-dwelling older women: a 14-year prospective study. Arch Intern Med 2003;163:2565-71.

36. Matthews CE, Jurj AL, Shu XO, Li HL, Yang G, Li Q, et al. Influence of exercise, walking, cycling, and overall non-exercise physical activity on mortality in Chinese women. Am J Epidemiol 2007;165:1343-50.

37. Andersen RE, Wadden TA, Bartlett SJ, Zemel B, Verde TJ, Franckowiak SC. Effects of lifestyle activity vs structured aerobic exercise in obese women: a randomized trial. JAMA 1999;281:335-40.

38. Basen-Engquist K, Taylor CL, Rosenblum C, Smith MA, Shinn EH, Greisinger A, et al. Randomized pilot test of a lifestyle physical activity intervention for breast cancer survivors. Patient Educ Couns 2006;64:225-34.

39. Shieh G. Suppression situations in multiple linear regression. Educ Psychol Meas 2006;66:435-47.

40. Wilcox S, Der Ananian C, Abbott J, Vrazel J, Ramsey C, Sharpe PA, et al. Perceived exercise barriers, enablers, and benefits among exercising and nonexercising adults with arthritis: results from a qualitative study. Arthritis Rheum 2006;55: 616-27.

41. Der Ananian C, Wilcox S, Saunders R, Watkins K, Evans A. Factors that influence exercise among adults with arthritis 
in three activity levels. Prev Chronic Dis [serial online]. 2006;3. URL: http://www.cdc.gov/pcd/issues/2006/jul/ 05 0220.htm.

42. Williams DA, Park KM, Ambrose KR, Clauw DJ. Assessor status influences pain recall. J Pain 2007;8:343-8.

43. Williams DA, Gendreau M, Hufford MR, Groner K, Gracely $\mathrm{RH}$, Clauw DJ. Pain assessment in patients with fibromyalgia syndrome: a consideration of methods for clinical trials. Clin J Pain 2004;20:348-56.

44. Zautra AJ, Fasman R, Parish BP, Davis MC. Daily fatigue in women with osteoarthritis, rheumatoid arthritis, and fibromyalgia. Pain 2007;128:128-35.

45. Syed IY, Davis BL. Obesity and osteoarthritis of the knee: hypotheses concerning the relationship between ground reaction forces and quadriceps fatigue in long-duration walking. Med Hypotheses 2000;54:182-5.

46. Rosemann T, Backenstrass M, Joest K, Rosemann A, Szecsenyi J, Laux G. Predictors of depression in a sample of 1,021 primary care patients with osteoarthritis. Arthritis Rheum 2007;57:415-22. 